\title{
Medical care contact for infertility and related medication use during pregnancy - a European, cross-sectional web-based study
}

\author{
Miljana Ilic ${ }^{1}$, Hedvig Nordeng ${ }^{1,2}$ and Angela Lupattelli ${ }^{1}$ \\ 1) PharmacoEpidemiology and Drug Safety Research Group, Department of Pharmacy, and PharmaTox \\ Strategic Research Initiative, Faculty of Mathematics and Natural Sciences, University of Oslo, Norway \\ 2) Department of Child Health and Development, Norwegian Institute of Public Health, Norway \\ Correspondence: Miljana Ilic, PharmacoEpidemiology and Drug Safety Research Group, Department of Pharmacy, University of Oslo, \\ PO Box 1068 Blindern, NO-0316 Oslo, Norway \\ E-mail: miljaniska@gmail.com
}

\begin{abstract}
Aims: The aim of the study was two-fold: i) to determine the prevalence of medical care contact for infertility in European countries; ii) to map overall and long-term/chronic medication use during pregnancy in women who sought medical care due to infertility.

Methods: This is a sub-study of the Multinational Medication Use in Pregnancy Study, a cross-sectional, web-based study conducted from October 2011 to February 2012. We included 8097 participants from Europe who were pregnant or new mothers. We collected data on overall and long-term/chronic medication use, medical care seeking due to infertility, and whether women eventually conceived spontaneously or with the aid of infertility treatment.

Results: Medical care contact for infertility was lower in Western Europe (prevalence estimate: $10.0-15.3 \%$ ), compared with Northern (15.2-17.5\%) or Eastern (17.4-20.9\%), but Poland had the lowest estimate (8.0\%). Overall, 660 (8.2\%) women sought medical care due to infertility but conceived spontaneously; $548(6.8 \%)$ conceived aided by fertility treatment, and $6889(85.0 \%)$ women did not seek help. Use of any medication was comparable across the three groups (range 80.4-82.5\%), but women seeking help for infertility (21.8$24.6 \%)$ took more often long-term/chronic medications than women who did not (14.8\%).

Conclusion: Medical care contacts for infertility varies greatly across European countries. Women who had medical contact due to infertility used more often chronic medications in pregnancy than women who did not, pointing to more co-morbidities and risk pregnancies.
\end{abstract}

This is an open access article distributed under the Creative Commons Attribution Licence, which permits unrestricted use, distribution, and reproduction in any medium, provided the original work is properly cited.

\section{INTRODUCTION}

Infertility represents a worldwide public health concern. Equal and equitable access to fertility care remains a challenge in most countries, particularly in those with low-middle income (1). Pooled data from worldwide surveys show a 12-month prevalence of infertility between $3.5-16.7 \%$ in more developed countries, and $6.9-9.3 \%$ in less developed countries (2). These data additionally indicate that $56.1 \%$ and $51.2 \%$ of couples in more or less developed countries, respectively, sought medical care because of problems with conceiving, but the proportion of couples actually receiving care was substantially smaller, $22.4 \%$ (2). Nevertheless, comparisons across countries are difficult due to different methods of data collection in the individual studies.

Women who undergo fertility treatment or seek medical help due to infertility are often older and have more chronic diseases than average pregnant women, and may therefore be more likely to need pharmacotherapy in pregnancy. One study showed that $12.7 \%$ of women undergoing fertility treatment filled at least one prescription for potential hazardous medications within 45 days after the beginning of a fertility cycle, compared to $6.8 \%$ of women who conceived spontaneously (3). In addition, these two groups had comparable intake of periconception folic acid, that is about $30 \%$, which is surprisingly low (3).

Women with fertility problems may have planned a pregnancy for years ahead. It is therefore possible that these women will be more careful in relation to smoking, drinking alcohol, or even in taking needed medications due to heightened fear for teratogenic effects on the unborn child. Yet, avoiding medications in pregnancy may sometimes jeopardize maternal-fetal health, for instance in women with diabetes, epilepsy, severe mental illnesses, or infections (4).

To date, no study has systematically characterized to what extent women seeking medical care due to infertility use medications, and in particular if differences do exist between women eventually conceiving spontaneously and those conceiving aided by fertility treatment. Filling this knowledge gaps is essential for prevention and preconception counselling, as eight out of ten women use at least one medication during the course of the pregnancy (5).

The aim of this study was two-fold: 1) to quantify the prevalence of medical care contact due to infertility in 


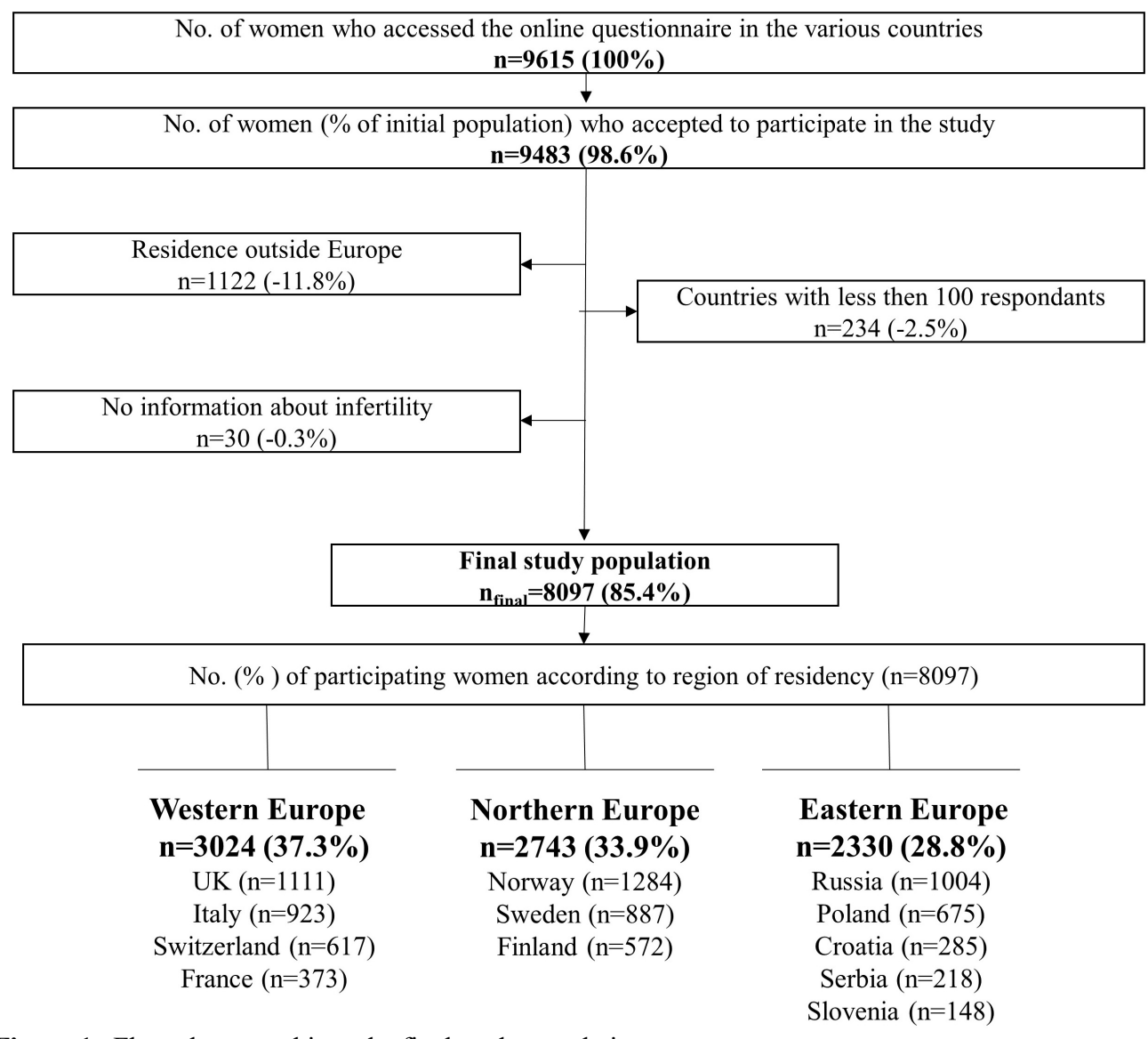

Figure 1. Flow chart to achieve the final study population.

European countries; 2) to determine the overall extent and type of medications taken during pregnancy, as well as for treatment of chronic/long-term disorders, according to medical care seeking due to infertility in multiple European countries.

\section{MATERIALS AND METHODS}

\section{Study population and data collection}

This is a sub-study of the 'Multinational Medication Use in Pregnancy Study, a multinational, cross-sectional, web-based investigation to examine patterns and correlates of medication use in pregnancy (5). Data were collected via a self-administered, anonymous, electronic questionnaire (www.questback.com) in 18 countries. Women located in Europe, North and South America and Australia who were pregnant or who had given birth less than a year ago were eligible to participate. The study was advertised on 2-3 pregnancy-related websites in each country, pregnancy forums and social media, and was open to the public for two months between October 2011 and February 2012 in each participating country. The recruitment national websites were selected for having the greatest number of daily users. The full questionnaire and further details about recruitment and the tools have been previously published (5).

Few responses were obtained from countries outside Europe, i.e. USA, Canada, Australia and South America, relative to the yearly birthing population in the countries. Hence, this specific study was limited to women residing in Europe at the time of study participation. To ensure that the study results are more representative of the target population in Europe, we further limited the study population to those countries with at least 100 respondents. An additional exclusion criterion was missing answer on the questions related to medical care contact due to infertility. Data selection to achieve the final study sample was performed as depicted in Figure 1.

\section{Medical care contact due to infertility}

Participants were asked whether they had contacted any healthcare provider due to infertility. Those who replied "yes" were additionally asked if they conceived with the aid of fertility treatment. Information from these two questions was used to define three mutually exclusive study groups: i) women who sought medical contact due to infertility and conceived aided by fertility treatment; ii) women who sought medical contact due to infertility but conceived spontaneously; iii) women who did not seek medical care due to infertility.

\section{Medication use during pregnancy}

Participants were confronted with a list of the most common chronic/long-term disorders (i.e. allergy, anxiety, asthma, cardiovascular disease, depression, diabetes, epilepsy, hypothyroidism, rheumatic disorders, other disorders), and asked whether they suffered/had 
suffered from these conditions during pregnancy. In case of an affirmative response, women were questioned about medication use for each individual indication as a free-text entry. It was optional to report timing of exposure for each of the medication use questions (the alternatives were gestational weeks 0-12 (1st trimester), 13-24 (2nd trimester) and 25-delivery (3rd trimester)). In addition, women were asked standardized questions about medication use for specific short-term illnesses (e.g., nausea, heartburn, constipation) and over-thecounter (OTC) drugs, as described earlier (5).

We defined a medicine as a single product containing one or more active ingredients. All recorded medications were coded into the corresponding Anatomical Therapeutic Chemical (ATC) codes at the ATC $5^{\text {th }}$ level (i.e. the substance level) whenever possible, otherwise into the $2^{\text {nd }}-4^{\text {th }}$ levels as appropriate, in accordance with the World Health Organization ATC index (6). Iron, mineral supplements, vitamins, herbal remedies and any type of alternative medicine were recorded separately and excluded from the estimation of medication use. Use of any medication, and medication for chronic/ long-term disorders during pregnancy constituted the outcome variables.

\section{Maternal characteristics}

The study collected information on multiple sociodemographics characteristics, including age, educational level, immigrant status, working status at time of conception, previous children, and marital status. Lifestyle factors included smoking status during pregnancy and alcohol consumption after awareness of pregnancy. Pregnancy characteristics included gestational week or weeks since childbirth at time of questionnaire response. In addition, women reported their country of residence at the time of study participation. For the latter variable, participating countries were grouped into the regions (1) Western Europe (including France, Italy, Switzerland, and the UK); (2) Northern Europe (including Finland, Norway and Sweden), (3) Eastern Europe (including Croatia, Poland, Russia, Serbia and Slovenia). In prior work, we have assessed the external validity of the study, by comparing socio-demographic and life-style characteristics of our study population on an individual country level with those of the general birthing population in the same country (5).

\section{Data analysis and statistics}

All statistical analyses were performed using Statistical Software for Data Science (Stata SE) version 16.0. Descriptive statistics were conducted to quantify the prevalence of medical care contact due to infertility in the countries involved in the study, as well as the proportions of medication use, overall and by chronic/longterm disorders. The chi-square test was used to compare the distribution of maternal sociodemographics and medication use between two independent groups at a time, that is: i) women who sought medical contact due to infertility and conceived aided by fertility treatment vs. women who did not seek medical care due to infertility; ii) women who sought medical contact due to infertility but conceived spontaneously vs. women who did not seek medical care due to infertility. A pvalue $<0.05$ was considered statistically significant.

\section{Ethics}

Informed consent was given by the participants by ticking the answer "yes" to the question "Are you willing to participate in the study?" The Regional Ethics Committee in Norway, region South-East, granted an ethical approval exemption for this study because of anonymity. Ethical approval or study notification to the relevant national Ethics Boards was achieved in the UK and Italy as required by the national legislation. All data were anonymous.

\section{RESUlTS}

\section{Population characteristics}

A total of 9615 women accessed the online questionnaire and reported their willingness to participate or not in the study; of these, $98.6 \%$ completed the electronic questionnaire. Figure 1 shows the data flow to achieve the final study population $(\mathrm{n}=8097)$.

Figure 2 shows the prevalence of medical care contact due to infertility, according to whether women eventually conceived spontaneously or conceived aided by fertility treatment. Overall, medical care contact for infertility, irrespective of conception means, ranged from $8.0 \%$ in Poland to $21.0 \%$ in Slovenia. The estimate was slightly lower in Western European countries (10.4-15.3\%), compared with the Nordic (15.2-17.5\%) or Eastern European countries except Poland (17.2$21.0 \%$ ). The largest proportion of women who conceived with the aid of fertility treatment ranged between $6.1 \%$ and $8.3 \%$ in most countries, but was lowest in Poland and the UK (4.1-4.3\%) and highest in Slovenia (12.1\%).

Table 1 shows the sociodemographic and life-style characteristics of the study population by medical care contact due to infertility. Women that sought medical help due to infertility had more often taken perinatal folate than those who did not. Women that conceived with the aid of fertility treatment were more often older, employed, married/cohabiting, and smoked or consumed alcohol during pregnancy to a lower extent than women who conceived spontaneously or did not seek care.

\section{Medication use during pregnancy}

Use of any medication during pregnancy was similar between women who sought or did not seek medical care due to infertility (Table 2). There were some differences in use of specific medications across the groups; regardless of whether women conceived with the aid of fertility treatment or spontaneously, those seeking medical care for infertility were significantly more often taking antithrombotic agents, antidiabetics, laxa- 


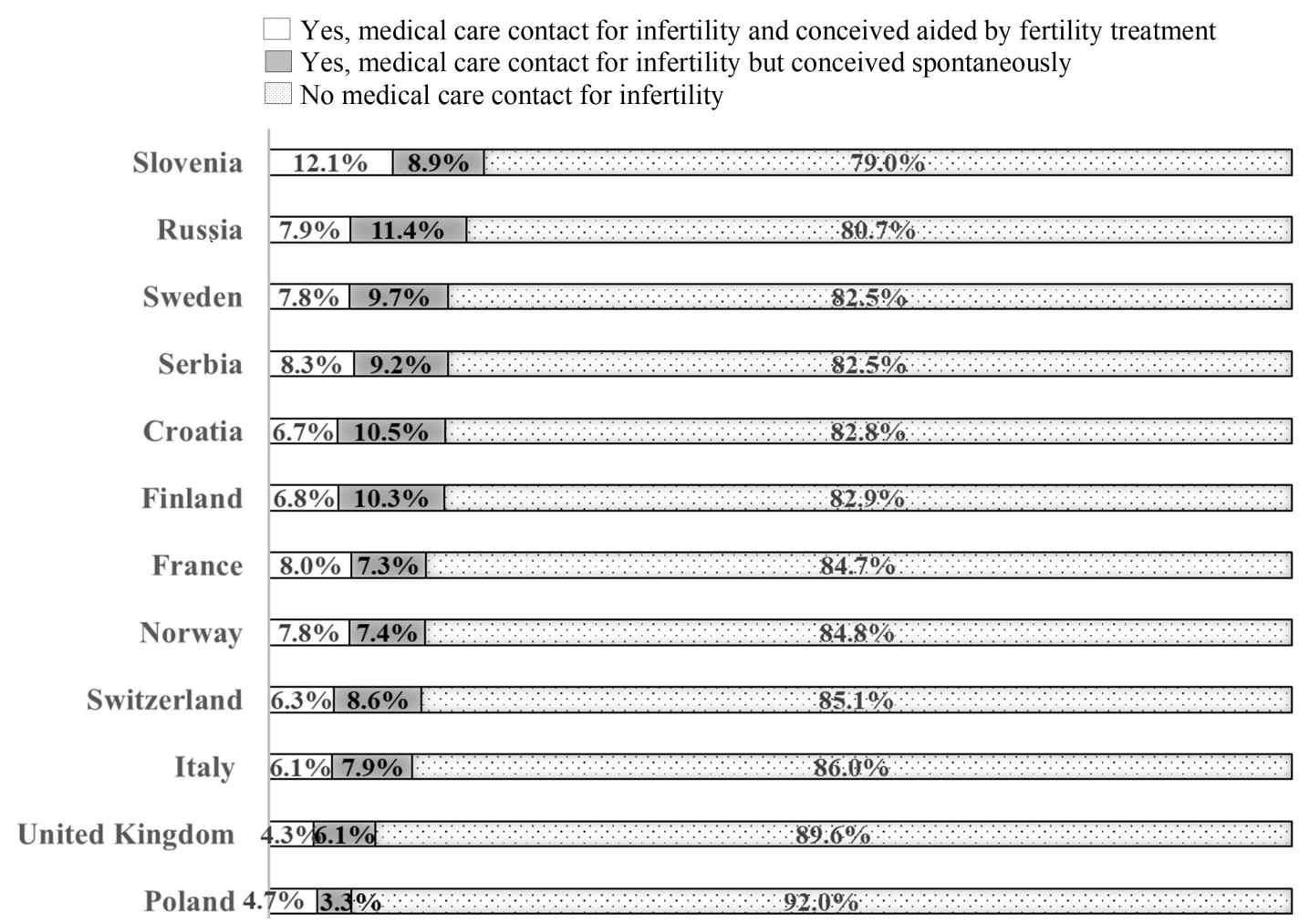

Figure 2. Prevalence of women seeking medical care due to infertility in European countries.

tives, thyroid hormones and systemic corticosteroids than those who did not have contact. Women who sought medical care but conceived spontaneously has a significantly greater use of sex hormones and drugs for obstructive airways diseases than women who did not seek medical care.

Table 3 shows the prevalence estimates of medication use for treatment of the most common chronic/ long-term disorders. Overall, use of medication for treatment of chronic/long-term disorders was significantly higher in women who sought medical care and conceived with the aid of fertility treatment $(24.6 \%)$ or spontaneously (21.8\%) relative to women who did not seek care (14.8\%). Thyroid hormone therapy was more than twice as high in women who sought medical help due to infertility compared to women who did not (pvalue $\leq 0.001$ ). Use of inhaled corticosteroid was significantly greater in women who sought medical care but conceived spontaneously (1.8\%) compared to $0.9 \%$ in other two groups. The same pattern was observed for nasal corticosteroids. Use of medication to treat depression was comparable across the three groups.

\section{DiscuSSION}

This is the first multinational study that explored medication use during pregnancy in women who had medical care contact due to infertility, and eventually had conceived either spontaneously or after fertility treatment. Because data were collected uniformly across countries, our estimates of medical care contact due to infertility are more comparable across countries in Europe, which is important from a public health perspective, but also in relation to access to care. Indeed, the negative implication of later parenthood on fertility, coupled to the growing range and availability of fertility treatments, is likely to influence help seeking and access to care due to infertility in Europe (7).

Our findings show that the prevalence of medical care contact due to infertility was generally lower in Western European countries (about 10-15\%) compared to both Northern (about 15-17\%) and Eastern European countries (about 17-21\%), with the latter ranking highest. Poland, however, was the only Eastern European country with low rate of medical contact rate due to infertility $(8.0 \%)$, which ranked lowest in the entire study. This finding is in line with prior research (8), and multiple factors can explain it, e.g., lack of public financing for diagnostics and treatment of infertility in Poland, or political and religion driven measures which limit women's and couples' access to fertility treatment (9).

The high incidence of sexually transmitted infections and pregnancy terminations in most Eastern European countries have been considered as contributing factors to the higher infertility prevalence in these countries, as also observed in this study (10). It is well known that sexually transmitted infections such as Chlamydia trachomatis and Neisseria gonorrhea can lead to infertility problems (11). Nevertheless, our estimates of medical care seeking due to infertility for the remaining countries were somewhat lower than what observed in prior research in Europe (8). This study by Olsen et al. (8) was conducted in 1991-1993, and so these prior 
Table 1. Maternal sociodemographic and life-style characteristics by medical care contact due to infertility.

\begin{tabular}{|c|c|c|c|c|c|c|c|c|}
\hline & \multicolumn{8}{|c|}{ Medical care contact due to infertility } \\
\hline & \multicolumn{2}{|c|}{$\begin{array}{c}\text { No, } \\
\mathrm{n}=6889\end{array}$} & \multicolumn{3}{|c|}{$\begin{array}{l}\text { Yes, but spontaneous } \\
\text { pregnancy, } n=660\end{array}$} & \multicolumn{3}{|c|}{$\begin{array}{l}\text { Yes, pregnancy aided } \\
\text { by } \mathrm{FT}, \mathrm{n}=548\end{array}$} \\
\hline & $\mathrm{n}$ & $\%$ & $\mathrm{n}$ & $\%$ & $\mathrm{p}$ value ${ }^{\mathrm{a}}$ & $\mathrm{n}$ & $\%$ & $\mathrm{p}$ value \\
\hline \multicolumn{9}{|l|}{ Pregnancy characteristics } \\
\hline \multicolumn{9}{|l|}{ Pregnancy trimester } \\
\hline $1^{\text {st }}$ trimester & 941 & 25.8 & 96 & 25.8 & 0.385 & 77 & 24.8 & 0.904 \\
\hline $2^{\text {nd }}$ trimester & 1467 & 40.3 & 162 & 43.5 & & 126 & 40.5 & \\
\hline $3^{\text {rd }}$ trimester & 1232 & 33.8 & 114 & 30.6 & & 108 & 34.7 & \\
\hline \multicolumn{9}{|l|}{ Weeks since childbirth } \\
\hline $0-12$ & 681 & 20.9 & 61 & 21.2 & 0.429 & 50 & 21.0 & 0.320 \\
\hline $13-24$ & 830 & 25.5 & 57 & 19.8 & & 48 & 20.2 & \\
\hline$\geq 25$ & 1783 & 54.9 & 170 & 59.0 & & 139 & 58.6 & \\
\hline Previous children (yes); no (\%) & 3471 & 50.4 & 326 & 49.4 & 0.627 & 173 & 31.6 & $\leq 0.001$ \\
\hline Perinatal use of folate (yes); ${ }^{c}$ no $(\%)$ & 6234 & 90.5 & 618 & 93.6 & 0.010 & 535 & 97.7 & $\leq 0.001$ \\
\hline \multicolumn{9}{|l|}{ Sociodemographic characteristics } \\
\hline \multicolumn{9}{|l|}{ Residence $^{d}$} \\
\hline Western Europe & 2630 & 38.2 & 221 & 33.5 & 0.057 & 173 & 31.6 & 0.007 \\
\hline Northern Europe & 2295 & 33.3 & 240 & 36.4 & & 208 & 37.9 & \\
\hline Eastern Europe & 1964 & 28.5 & 199 & 30.2 & & 167 & 30.4 & \\
\hline \multicolumn{9}{|l|}{ Maternal age } \\
\hline$\leq 20$ years & 231 & 3.35 & $<5$ & & $\leq 0.001$ & $<5$ & & $\leq 0.001$ \\
\hline $21-30$ years & 3937 & 57.1 & 309 & 46.8 & & 210 & 38.3 & \\
\hline$\geq 31$ years & 2721 & 39.5 & 347 & 52.6 & & 337 & 61.5 & \\
\hline \multicolumn{9}{|l|}{ Marital status } \\
\hline Married/cohabiting & 6521 & 94.6 & 631 & 95.5 & 0.297 & 534 & 97.4 & 0.004 \\
\hline Other than above & 368 & 5.3 & 29 & 4.4 & & 14 & 2.5 & \\
\hline \multicolumn{9}{|l|}{ Working status at conception; no (\%) } \\
\hline Employed & 4118 & 59.9 & 412 & 62.4 & 0.087 & 372 & 67.8 & $\leq 0.001$ \\
\hline Student & 639 & 9.3 & 39 & 5.9 & & 22 & 4.0 & \\
\hline $\mathrm{HCP}$ & 904 & 13.1 & 94 & 14.2 & & 87 & 15.8 & \\
\hline Homemaker & 563 & 8.2 & 50 & 7.6 & & 22 & 4.0 & \\
\hline Job seeker/others & 306 & 4.4 & 33 & 5.0 & & 23 & 4.2 & \\
\hline \multicolumn{9}{|l|}{ Educational attainment; no (\%) } \\
\hline$<$ High school & 300 & 4.3 & 21 & 3.2 & 0.012 & 12 & 2.2 & $\leq 0.001$ \\
\hline High school & 1988 & 28.9 & 170 & 25.8 & & 117 & 21.3 & \\
\hline$>$ High school & 3781 & 54.8 & 405 & 61.4 & & 354 & 64.6 & \\
\hline Immigrant status (yes); ${ }^{e}$ no (\%) & 377 & 5.5 & 48 & 7.3 & 0.053 & 26 & 4.7 & 0.469 \\
\hline \multicolumn{9}{|l|}{ Life-style characteristics } \\
\hline $\begin{array}{l}\text { Alcohol use during pregnancy } \\
(\mathrm{yes}) ;{ }^{f} \text { no }(\%)\end{array}$ & 1146 & 16.6 & 94 & 14.3 & 0.214 & 52 & 9.5 & $\leq 0.001$ \\
\hline $\begin{array}{l}\text { Smoking during pregnancy (yes); } \\
\text { no }(\%)\end{array}$ & 654 & 9.5 & 59 & 8.9 & 0.668 & 35 & 6.4 & 0.017 \\
\hline
\end{tabular}

Numbers may not add up due to missing values.

Abbreviations: $\mathrm{FT}=$ Fertility treatment; $\mathrm{HCP}=$ Health Care professional.

${ }^{a} \mathrm{p}$ value for the comparison between group fertility contact, but spontaneous pregnancy versus no fertility contact

${ }^{b} \mathrm{p}$ value for the comparison between group fertility contact with pregnancy aided by fertility treatment versus no fertility contact

${ }^{c}$ Indicates use of folate before and/or during pregnancy

${ }^{d}$ Western Europe included UK, Italy, Switzerland, France; Northern Europe included Norway, Sweden, Finland; Eastern Europe included

Russia, Poland, Croatia, Serbia, Slovenia

${ }^{\mathrm{e}}$ Women having the first language different from the official main language in the country of residence

${ }^{f}$ Indicates alcohol consumption after awareness of the pregnancy.

results may not be directly comparable to ours due to the long time difference in recruitment. In Olsen et al. (8), women were asked to report about medical contact due to infertility for themselves and their male partners, while our study did not enquire about the partner having problems, and this could additionally explain our lower estimates (8). This could explain the discrepancies between the studies, as fertility problems are in about a third of the cases attributable to males (12). Further- more, we cannot exclude the risk that bias due to social desirability could have affected our results, given the sensitive nature of the question on fertility issues. Even though highly educated are more likely to seek medical help due to infertility compared to those who have lower education levels $(13,14)$, this factor is unlikely to explain our lower estimates of medical care contact due to infertility in Western and Norther Europe, as our sample included more often women with higher educa- 
Table 2. Overall medication use on $2^{\text {nd }}$ ATC level according to medical care contact due to infertility.

\begin{tabular}{|c|c|c|c|c|c|c|c|c|c|}
\hline & \multirow[b]{3}{*}{ Medication use by ATC, $2^{\text {nd }}$ level } & \multicolumn{8}{|c|}{ Medical care contact due to infertility } \\
\hline & & \multicolumn{2}{|c|}{$\begin{array}{c}\text { No } \\
\mathrm{n}=6889\end{array}$} & \multicolumn{3}{|c|}{$\begin{array}{c}\text { Yes, but conceived } \\
\text { spontaneously } \\
n=660\end{array}$} & \multicolumn{3}{|c|}{$\begin{array}{l}\text { Yes, and conceived } \\
\text { aided by FT } \\
n=548\end{array}$} \\
\hline & & $\mathrm{n}$ & $\%$ & $\mathrm{n}$ & $\%$ & p value ${ }^{a}$ & $\mathrm{n}$ & $\%$ & $p_{\text {value }}^{b}$ \\
\hline $\mathbf{A}$ & Alimentary tract and metabolism & & & & & & & & \\
\hline A01 & Stomatological preparations & 51 & 0.7 & 5 & 0.8 & 0.961 & 5 & 0.9 & 0.654 \\
\hline A02 & Drugs for acid related disorders & 2341 & 34.0 & 226 & 34.2 & 0.893 & 175 & 31.9 & 0.330 \\
\hline A03 & Drugs for functional gastrointestinal disorders & 447 & 6.5 & 39 & 5.9 & 0.562 & 48 & 8.8 & 0.040 \\
\hline A04 & Antiemetics and antinauseants & 70 & 1.0 & 9 & 1.4 & 0.402 & 6 & 1.1 & 0.860 \\
\hline A05 & Bile and liver therapy & 14 & 0.2 & 6 & 0.9 & 0.001 & $<5$ & & 0.432 \\
\hline A06 & Laxatives & 851 & 9.9 & 86 & 13.0 & 0.011 & 82 & 15.0 & $<0.001$ \\
\hline A07 & $\begin{array}{l}\text { Antidiarrheals, intestinal } \\
\text { antiinflammatory/antiinfective agents }\end{array}$ & 67 & 1.0 & 6 & 0.9 & 0.874 & 4 & 0.7 & 0.547 \\
\hline A10 & Drugs used in diabetes & 32 & 0.5 & 9 & 1.4 & 0.003 & 20 & 3.6 & $<0.001$ \\
\hline B & Blood and blood forming organs & & & & & & & & \\
\hline B01 & Antithrombotic agents & 86 & 1.1 & 16 & 2.4 & 0.012 & 15 & 2.7 & 0.004 \\
\hline $\mathbf{C}$ & Cardiovascular system & & & & & & & & \\
\hline $\mathrm{C} 02$ & Antihypertensives & 31 & 0.4 & $<5$ & & 0.573 & 5 & 0.9 & 0.383 \\
\hline $\mathrm{C} 07$ & Beta blocking agents & 54 & 0.8 & 7 & 1.2 & 0.448 & $<5$ & & 0.890 \\
\hline D & Dermatologicals & & & & & & & & \\
\hline D01 & Antifungals for dermatological use & 25 & 0.4 & $<5$ & & 0.335 & $<5$ & & 0.185 \\
\hline D07 & Corticosteroids, dermatological preparations & 40 & 0.6 & 6 & 0.9 & 0.300 & $<5$ & & 0.661 \\
\hline G & Genitourinary system and sex hormones & & & & & & & & \\
\hline G01 & Gynaecological antiinfective and antiseptics & 292 & 4.2 & 32 & 4.8 & 0.460 & 28 & 5.1 & 0.334 \\
\hline G03 & Sex hormones and modulators of the genital system & 45 & 0.6 & 11 & 1.7 & 0.004 & 7 & 1.3 & 0.091 \\
\hline $\mathbf{H}$ & $\begin{array}{l}\text { Systematic hormonal preparations, excl. sex } \\
\text { hormones and insulins }\end{array}$ & & & & & & & & \\
\hline H02 & Corticosteroids for systemic use & 51 & 0.7 & 13 & 2.0 & 0.001 & 10 & 1.8 & 0.007 \\
\hline H03 & Thyroid therapy & 237 & 3.4 & 49 & 7.4 & $<0.001$ & 51 & 9.3 & $<0.001$ \\
\hline $\mathbf{J}$ & Anti-infective for systematic use & & & & & & & & \\
\hline $\mathrm{J} 01$ & Antibacterials for systemic use & 947 & 13.7 & 99 & 15.0 & 0.373 & 66 & 12.0 & 0.263 \\
\hline $\mathbf{L}$ & Antineoplastic and immunomodulating agents & & & & & & & & \\
\hline L03 & Immunostimulants & 77 & 1.1 & 11 & 1.7 & 0.209 & 8 & 1.5 & 0.468 \\
\hline M & Musculo-skeletal system & & & & & & & & \\
\hline M01 & Antiinflamatory and antirheumatic products & 330 & 4.8 & 31 & 4.7 & 0.915 & 22 & 4.0 & 0.411 \\
\hline $\mathbf{N}$ & Nervous system & & & & & & & & \\
\hline N02 & Analgesics & 3794 & 55.1 & 365 & 55.3 & 0.910 & 290 & 55.9 & 0.329 \\
\hline N05 & Psycholeptics & 136 & 2.0 & 16 & 2.4 & 0.432 & 9 & 1.6 & 0.589 \\
\hline N06 & Psychoanaleptics & 158 & 2.3 & 19 & 2.9 & 0.342 & 13 & 2.4 & 0.906 \\
\hline $\mathbf{R}$ & Respiratory system & & & & & & & & \\
\hline R01 & Nasal preparations & 1193 & 17.3 & 130 & 19.7 & 0.125 & 108 & 19.7 & 0.244 \\
\hline R02 & Throat preparations & 135 & 2.0 & 16 & 2.4 & 0.415 & 11 & 2.0 & 0.938 \\
\hline R03 & Drugs for obstructive airway diseases & 248 & 3.6 & 37 & 5.6 & 0.010 & 14 & 4.4 & 0.349 \\
\hline R05 & Cough and cold preparations & 108 & 1.6 & 8 & 1.2 & 0.478 & 5 & 0.9 & 0.227 \\
\hline R06 & Antihistamines for systemic use & 588 & 8.5 & 66 & 10.0 & 0.201 & 51 & 9.3 & 0.535 \\
\hline & Total medication use (any ATC) & 5541 & 80.4 & 537 & 81.4 & 0.564 & 452 & 82.5 & 0.243 \\
\hline
\end{tabular}

Abbreviation: $\mathrm{ATC}=$ Anatomical Therapeutic Chemical codes.

The most common medication groups within each ATC class are in italics. Medication groups used by less than three women in any of the groups, are not presented. Estimates do not include mineral supplements, vitamins, iron, and herbal or alternative medicine products.

${ }^{a} \mathrm{p}$-value for the comparison between group fertility contact, but spontaneous pregnancy versus no fertility contact

${ }^{b} \mathrm{p}$-value for the comparison between group fertility contact with pregnancy aided by fertility treatment versus no fertility contact

tion than the general birthing population.

We found a comparable prevalence of any medication use in pregnancy across groups, which was common (about $80 \%$ ) regardless of medical care contact due to infertility and conception measures. This finding is in line with other studies examining prevalence of medication use in pregnant women in USA and Europe (15-21), and suggests that having medical contact due to infertility does not relate to greater or lower medication use in pregnancy. At the same time, we observed that use of long-term/chronic medication was higher in women who sought help due to infertility (21.8-24.6\%), 
Table 3. Prevalence of medication use for chronic/long-term disorders in pregnancy, overall and by drug groups, according to medical care contact due to infertility.

\begin{tabular}{|c|c|c|c|c|c|c|c|c|}
\hline & \multicolumn{8}{|c|}{ Medical care contact due to infertility } \\
\hline & \multicolumn{2}{|c|}{$\begin{array}{c}\text { No } \\
\mathrm{n}=6889\end{array}$} & \multicolumn{3}{|c|}{$\begin{array}{c}\text { Yes, but conceived } \\
\text { spontaneously } \\
n=660\end{array}$} & \multicolumn{3}{|c|}{$\begin{array}{c}\text { Yes, and conceived } \\
\text { aided by FT } \\
n=548\end{array}$} \\
\hline & $\mathbf{n}$ & $\%$ & $\mathbf{n}$ & $\%$ & p value ${ }^{a}$ & $\mathbf{n}$ & $\%$ & p value ${ }^{b}$ \\
\hline Medication use for hypothyroidism, total & 218 & 3.2 & 46 & 6.9 & $\leq \mathbf{0 . 0 0 1}$ & 47 & 8.6 & $\leq \mathbf{0 . 0 0 1}$ \\
\hline Levothyroxine (H03AA01) & 209 & 3.0 & 41 & 6.2 & $\leq 0.001$ & 45 & 8.2 & $\leq 0.001$ \\
\hline Medication use for asthma, total & 236 & 3.4 & 28 & 4.2 & 0.275 & 20 & 3.6 & 0.782 \\
\hline Inhalant selective beta- 2 agonists (R03AC) & 150 & 2.2 & 20 & 3.0 & 0.158 & 10 & 1.8 & 0.584 \\
\hline Adrenergic and other drugs for COPD (R03AK) & 72 & 1.0 & 7 & 1.1 & 0.970 & 7 & 1.3 & 0.610 \\
\hline Inhalant glucocorticoids (R03BA) & 60 & 0.9 & 12 & 1.8 & 0.017 & 5 & 0.9 & 0.920 \\
\hline Systemic selective beta- 2 agonists (R03CC) & 23 & 0.3 & 5 & 0.8 & 0.087 & $<5$ & & 0.548 \\
\hline Medication use for allergy, total & 223 & 3.2 & 38 & 5.8 & 0.001 & 27 & 4.9 & 0.035 \\
\hline Nasal corticosteroids (R01AD) & 39 & 0.6 & 13 & 2.0 & $\leq 0.001$ & 5 & 0.9 & 0.309 \\
\hline Antihistamines (R06AE) & 80 & 1.2 & 11 & 1.7 & 0.256 & 8 & 1.5 & 0.534 \\
\hline Antihistamines (R06AX) & 49 & 0.7 & 7 & 1.1 & 0.318 & 8 & 1.5 & 0.053 \\
\hline Ophthalmologic antiallergics (S01GX) & 16 & 0.2 & $<5$ & & 0.814 & $<5$ & & 0.722 \\
\hline Medication use for depression, total & 126 & 1.8 & 15 & 2.3 & 0.421 & 13 & 2.4 & 0.366 \\
\hline SSRI antidepressants (N06AB) & 97 & 1.4 & 12 & 1.8 & 0.399 & 8 & 1.5 & 0.921 \\
\hline SNRIs/mianserin/trazodone/mirtazapine/bupropion & 15 & 0.2 & $<5$ & & 0.659 & $<5$ & & 0.487 \\
\hline Anxiolytics, benzodiazepine (N05BA) & 9 & 0.1 & $<5$ & & - & $<5$ & & 0.019 \\
\hline $\begin{array}{l}\text { Total medication use for any chronic/long-term } \\
\text { disorder }\end{array}$ & 1025 & 14.8 & 144 & 21.8 & $\leq \mathbf{0 . 0 0 1}$ & 135 & 24.6 & $\leq \mathbf{0 . 0 0 1}$ \\
\hline
\end{tabular}

${ }^{a}$ p-value for the comparison between group fertility contact, but spontaneous pregnancy versus no fertility contact

${ }^{b}$ p-value for the comparison between group fertility contact with pregnancy aided by fertility treatment versus no fertility contact

* Sums of percentages do not add up to total medication use as only most common medication groups are presented. Estimates do not include mineral supplements, vitamins, iron, and herbal or alternative medicine products.

Abbreviations: COPD: Chronic obstructive pulmonary disease; SSRI: Selective serotonin re-uptake inhibitors; SNRI: Serotonin-noradrenaline reuptake inhibitors.

regardless of the conception measure, compared with women not seeking care (14.8\%). These medications included antithrombotic agents, systemic corticosteroids, antidiabetic medications, and thyroid hormones. The more elevated use of thyroid medication in women seeking fertility help is not surprising since hypothyroidism is a known risk factor for subfertility (22). Similarly, use of antithrombotic medications is a marker for underlying cardiovascular disorders that may affect women's ability to conceive (23) or are related with recurrent pregnancy losses. However, we cannot exclude that antithrombotics were taken in conjunction with the received fertility treatment (24). Our results regarding medication use for diabetes are in line with prior research showing a link between diabetes and reduced fertility (25). Further, the higher prevalence of antidiabetic medications use in women who sought help due to infertility could be explained by metformin being used in ovulation induction (26).

The higher proportion of asthma and allergy medications, including inhaled glucocorticoids, systemic selective beta- 2 agonists and nasal corticosteroids, in women with medical care contact due to infertility who however conceived spontaneously, are somewhat surprising. Indeed, these estimates of medication use were greater than in women who conceived after fertility treatment. Results of a systematic review indicate an association between asthma and reduced fertility (number of offspring, time to pregnancy and need for fertility treatment) (27). A case-control study conducted in USA and Canada reports that women who had used asthma medication for more than 6 months had a statistically significant increased risk of infertility (magnitude of risk: 1.7) (28). Other studies also reported higher need for fertility treatment among women with asthma (29, 30 ), however a recent study showed that only women taking asthma medications on daily basis plus extra dosing for symptoms (i.e., combination of inhaled corticosteroid and long-acting beta-agonists) have a small reduction in fecundability (31). Taken together, these findings may suggest that most women using asthma and/or allergy medications are more likely to encounter fertility problems, but they eventually conceive spontaneously without the need of fertility treatment.

One prior study in Israel reported that $12.7 \%$ of women who underwent fertility treatment filled at least one prescription of potentially hazardous medications, compared to $6.8 \%$ of women who spontaneously got pregnant (3). Most used medications were statins, ACE inhibitors in women who underwent fertility treatment, compared to isotretinoin and tetracyclines in women who got spontaneously pregnant (3). This finding could not be substantiated in our study, as these drugs constituted very rare exposures and therefore not presented in 
the results. However, given our results, we argue that women seeking care due to infertility have often underlying chronic disorders, which require treatment with medications that may be classified as potentially harmful. Yet, use of these medications may still be appropriate for the individual women to safeguard maternal-fetal health.

\section{Strengths and limitations}

The study has strengths and limitations that need mentioning. One advantage is uniform data collection across countries, which facilitates comparability of estimates. The study was web-based, which enabled us to reach a high number of participants. Information about the study was available on many of internet pages frequently used by pregnant women, something that made the number of potential participants even higher. Because the study was anonymous, it is likely that women answered sensitive questions (such as alcohol use or smoking in pregnancy, and even seeking help due to fertility problems), more truthfully than what could happen in a face-to-face interview. One additional strength is that questions about medication use were phrased according to indication, including for treatment of long-term/chronic illnesses in pregnancy, which may have enhanced recall of drug use.

One study limitation is that our study population had on average higher education than the general birthing population in the countries examined, which may have affected the prevalence of medical contact for infertility or medication use in pregnancy. The study used an electronic questionnaire, which may have led to recruitment of more educated and resourceful women; this risk of selection bias limits the extent to which the results are representative of the target population. However, epidemiological studies indicate reasonable validity of web-based recruitment methods (32-35). Also, the penetration rate of the internet either in households or at work is relatively high among women in childbearing age (36). We have previously assessed the study's external validity on an individual country level and found that on average, the women in the study had higher education and were slightly more often primiparous than the general birthing populations in the various countries (5). In specific countries (i.e., France and Russia) the study sample was a small proportion of the general birthing population; hence the generalizability of our findings for these specific countries should be interpreted with caution (5). Further, all disorders and medication use in this study were self-reported by participants, and thus dependent on these women's perception of the medical conditions and recall of medication use. Since many acute ailments requiring pharmacotherapy occur in mid or late pregnancy, inclusion of pregnant women at early gestation in the total material may have reduced the prevalence of medication user during pregnancy. We have previously shown that time of recruitment does not influence the proportion of chronic/long-term medication use in this study (5). Moreover, the questions regarding infertility were only related to women and not their partners, and the study did not ask women about the infertility method used. The study did not recruit women from all European countries, and so our results may not be generalizable to the entire population of pregnant women in Europe. In addition, as the study included women who eventually got pregnant, our results on medical care seeking due to infertility do not include women with fertility problems that do not succeed to conceive.

\section{CONCLUSION}

Medical care contacts for infertility varies greatly across European countries. Use of medications was common in pregnant women, regardless of whether they sought fertility help or not and of how the pregnancy was achieved. Women who had medical contact due to infertility used more often chronic medications in pregnancy than women who did not, pointing to more comorbidities and risk pregnancies. Tailored counselling regarding risks and benefits of medication use in pregnancy due to chronic diseases should be prioritized in these women, in order to enhance appropriate drug treatment and safeguard the health of both mother and her unborn child.

\section{Funding}

This research was funded by the University of Oslo and by the Foundation for Promotion of Norwegian Pharmacies and the Norwegian Pharmaceutical Society. H.N. is funded by the European Research Council (ERC) Starting Grant "DrugsInPregnancy" (grant number 678033). A.L. is funded by the Research Council of Norway, FRIMEDBIO (grant number 288696). MI receive a research stipend by the Norwegian Society for Pharmacoepidemiology.

\section{Acknowledgements}

We thank all the participating women who took part in this study and the national study coordinators (Spigset O, Twigg MJ, Zagorodnikova K, Mårdby AC, Moretti ME, Drozd M, Panchaud A, Hameen-Anttila K, Rieutord A, Gjergja Juraski R, Odalovic M, Kennedy D, Rudolf G, Passier JLM, Juch H and Björnsdóttir I). We thank all website providers who contributed to the recruitment phase.

\section{Conflicts of interest}

The authors declare no conflict of interest.

This paper is based on a master's thesis from the University of Oslo, 2020:

Miljana Ilic: Use of medication and characteristics of pregnant women who sought medical attention due to infertility: an European, web-based cross-sectional study. 


\section{REFERENCES}

1. WHO. Infertility, 2020. Accessed March 16, 2020. [Available from: https://www.who.int/news-room/factsheets/detail/infertility].

2. Boivin J, Bunting L, Collins JA, Nygren KG. International estimates of infertility prevalence and treatmentseeking: potential need and demand for infertility medical care. Hum Reprod 2007;22(6):1506-12.

3. Riskin-Mashiah S, Auslender R. Periconceptional folic acid and teratogenic drug use in women undergoing fertility treatments. J Matern Fetal Neonatal Med 2012;25(10):1899-903.

4. Elseviers M. Drug utilization research: methods and applications. Chichester, West Sussex, Hoboken, NJ: John Wiley \& Sons, 2016.

5. Lupattelli A, Spigset O, Twigg MJ, Zagorodnikova K, Mardby AC, Moretti ME, et al. Medication use in pregnancy: a cross-sectional, multinational web-based study. BMJ Open 2014;4(2):e004365.

6. WHO Collaborating Centre for Drugs Statistics Methodology. ATC/DDD Index 2021. Accessed January 20, 2020. [Available from: https://www.whocc.no/atc_ddd_index/].

7. Mills M, Rindfuss RR, McDonald P, te Velde E, ESHRE Reproduction and Society Task Force. Why do people postpone parenthood? Reasons and social policy incentives. Hum Reprod Update 2011;17(6):848-60.

8. Olsen J, Küppers-Chinnow M, Spinelli A. Seeking medical help for subfecundity: a study based upon surveys in five European countries. Fertil Steril 1996;66(1):95-100.

9. Korolczuk E. 'The purest citizens' and 'IVF children'. Reproductive citizenship in contemporary Poland. RBMS 2016;3:126-33.

10. Lazdane G. Low-fertility-The future of Europe? Entre Nous Cph Den. 2006;No.63:6.

11. Tsevat DG, Wiesenfeld HC, Parks C, Peipert JF. Sexually transmitted diseases and infertility. Am J Obstet Gynecol 2017;216(1):1-9.

12. Sharlip ID, Jarow JP, Belker AM, Lipshultz LI, Sigman M, Thomas AJ, et al. Best practice policies for male infertility. Fertil Steril 2002;77(5):873-82.

13. Terävä A-N, Gissler M, Hemminki E, Luoto R. Infertility and the use of infertility treatments in Finland: Prevalence and socio-demographic determinants 1992-2004. Eur J Obstet Gynecol Reprod Biol 2008;136(1):61-6.

14. Bunting L, Boivin J. Decision-making about seeking medical advice in an internet sample of women trying to get pregnant. Hum Reprod 2007;22(6):1662-8.

15. Mitchell AA, Gilboa SM, Werler MM, Kelley KE, Louik C, Hernandez-Diaz S. Medication use during pregnancy, with particular focus on prescription drugs: 1976-2008. Am J Obstet Gynecol 2011;205(1):51.e1-8.

16. Bakker M, Jentink J, Vroom F, Van Den Berg P, De Walle H, De Jong-Van Den Berg L. Maternal medicine: Drug prescription patterns before, during and after pregnancy for chronic, occasional and pregnancy-related drugs in the Netherlands. BJOG 2006;113(5):559-68.

17. Lacroix I, Damase-Michel C, Lapeyre-Mestre M, Montastruc JL. Prescription of drugs during pregnancy in France. Lancet 2000;356(9243):1735-6.

18. Nordeng H, Jacobsen G, Nesheim B-I, Eskild A. Drug use in pregnancy among parous Scandinavian women. Norsk Epidemiologi 2001;11(1):99-102.

19. Donati S, Baglio G, Spinelli A, Grandolfo ME. Drug use in pregnancy among Italian women. Eur J Clin Pharmacol 2000;56(4):323-8.

20. Egen-Lappe V, Hasford J. Drug prescription in pregnancy: analysis of a large statutory sickness fund population. Eur J Clin Pharmacol 2004;60(9):659-66.

21. De Jong-van den Berg LT, Van den Berg PB, Haaijer-Ruskamp FM, Dukes MN, Wesseling H. Investigating drug use in pregnancy. Methodological problems and perspectives. Pharm Weekbl Sci 1991;13(1):32-8.

22. Koyyada A, Orsu P. Role of hypothyroidism and associated pathways in pregnancy and infertility: Clinical insights. Tzu Chi Med J 2020;32(4):312-7.

23. de Jong PG, Goddijn M, Middeldorp S. Antithrombotic therapy for pregnancy loss. Hum Reprod Update 2013; 19(6):656-73.

24. Di Micco P, Russo V, Mastroiacovo D, Bosevski M, Lodigiani C. In vitro fertilization procedures with embryo transfer and their association with thrombophilia, thrombosis and early antithrombotic treatments. $J$ Blood Med 2020;11:185-90.

25. Jonasson JM, Brismar K, Sparén P, Lambe M, Nyrén O, Östenson C-G, et al. Fertility in women with type 1 diabetes. Diabetes Care 2007;30(9):2271.

26. Nestler JE. Metformin in the treatment of infertility in polycystic ovarian syndrome: an alternative perspective. Fertil Steril 2008;90(1):14-6.

27. Bláfoss J, Hansen AV, Malchau Lauesgaard SS, Ali Z, Ulrik CS. Female asthma and atopy - impact on fertility: a systematic review. $J$ Asthma Allergy 2019;12:205-11.

28. Grodstein F, Goldman MB, Ryan L, Cramer DW. Self-reported use of pharmaceuticals and primary ovulatory infertility. Epidemiology 1993;4(2):151-6. 
29. Sheiner E, Mazor M, Levy A, Wiznitzer A, Bashiri A. Pregnancy outcome of asthmatic patients: a populationbased study. J Matern Fetal Neonatal Med 2005;18(4):237-40.

30. Vejen Hansen A, Ali Z, Malchau SS, Blafoss J, Pinborg A, Ulrik CS. Fertility treatment among women with asthma: a case-control study of 3689 women with live births. Eur Respir J 2019;53(2):3-5.

31. Crowe HM, Wise LA, Wesselink AK, Rothman KJ, Mikkelsen EM, Sørensen HT, et al. Association of asthma diagnosis and medication use with fecundability: A prospective cohort study. Clin Epidemiol 2020;12:579-87.

32. Ekman A, Dickman PW, Klint A, Weiderpass E, Litton JE. Feasibility of using web-based questionnaires in large population-based epidemiological studies. Eur J Epidemiol 2006;21(2):103-11.

33. van Gelder M, van de Belt TH, Engelen L, Hooijer R, Bredie SJH, Roeleveld N. Google AdWords and Facebook ads for recruitment of pregnant women into a prospective cohort study with long-term follow-up. Matern Child Health $J$ 2019;23(10):1285-91.

34. van Gelder M, Vorstenbosch S, Te Winkel B, van Puijenbroek EP, Roeleveld N. Using web-based questionnaires to assess medication use during pregnancy: A validation study in 2 prospectively enrolled cohorts. $\mathrm{Am} \mathrm{J}$ Epidemiol 2018;187(2):326-36.

35. van Gelder MM, Bretveld RW, Roeleveld N. Web-based questionnaires: The future in epidemiology? Am J Epidemiol 2010;172(11):1292-8.

36. Seybert H. Internet use in households and by individuals in 2011. Eurostat Statistics in focus 2011. Accessed 30 Janury 2013. [Available from: http://ec.europa.eu/eurostat/documents/3433488/5579964/KS-SF-11-066EN.PDF/090e071f-c3a9-45d8-aa90-9b142251fd3a?version=1.0. 